2011

\title{
Spreadsheets Across the Curriculum, 3: Finding a List of Mathematical Skills for Quantitative Literacy Empirically
}

\author{
H L. Vacher \\ Department of Geology, University of South Florida, vacher@usf.edu \\ Emily Lardner \\ The Evergreen State College, Olympia WA, emily.lardner@ghc.edu
}

Follow this and additional works at: https://digitalcommons.usf.edu/numeracy

Part of the Mathematics Commons, and the Science and Mathematics Education Commons

\section{Recommended Citation}

Vacher, H L., and Emily Lardner. "Spreadsheets Across the Curriculum, 3: Finding a List of Mathematical Skills for Quantitative Literacy Empirically." Numeracy 4, Iss. 1 (2011): Article 5. DOI: http://dx.doi.org/ 10.5038/1936-4660.4.1.5 


\title{
Spreadsheets Across the Curriculum, 3: Finding a List of Mathematical Skills for Quantitative Literacy Empirically
}

\begin{abstract}
What mathematical topics do educators committed to teaching mathematics in context choose for their students when given the opportunity to develop an educational resource explicitly to teach mathematics in context? This paper examines the choices made for the 55 modules by 40 authors in the General Collection of the Spreadsheets Across the Curriculum (SSAC) library. About half of the modules were made by authors from natural science, and about $60 \%$ of the other modules were by authors from mathematics. The modules are tagged with terms of a search vocabulary developed for the browse page of the collection. The four terms most frequently used to tag the modules are: visual display of data (particularly XY plots and bar graphs); ratio and proportion; rates; and forward modeling (e.g., what-if?). Subdividing the modules into those authored by instructors from mathematics vs. natural science vs. other disciplines shows universal popularity of the first three choices. Forward modeling was a favorite of authors from mathematics and natural science. Manipulating equations, unit conversions, and logarithms (orders of magnitude, scientific notation) were called for by authors from natural science. The paper concludes with a list of 15 concepts and skills that received the most "votes."
\end{abstract}

\section{Keywords}

quantitative literacy, spreadsheets

\section{Creative Commons License}

\section{c) (7) (8)}

This work is licensed under a Creative Commons Attribution-Noncommercial 4.0 License

\section{Cover Page Footnote}

Len Vacher is a professor of geology at the University of South Florida. He is a Fellow of the Geological Society of America and the 2004 recipient of the National Association of Geoscience Teachers' Neil Miner Award. He served on the charter board of the NNN and currently co-edits this journal.

Emily Lardner is co-Director of the Washington Center for Improving Undergraduate Education, a public service center based at The Evergreen State College, where she also teaches academic writing. The Washington Center is charged with improving undergraduate education in the state of Washington and beyond. It serves as a national resource center for learning communities across the curriculum. 
In other words, we don't know if we are becoming more or less numerate, because we are not sure what we mean by numeracy and we haven't got good data anyway on how we did earlier.

MacNeal (1994, p. 132), referring to a passage in the book by Cohen (1982)

\section{Introduction}

One way to communicate what one means by numeracy (or Quantitative Literacy, [QL]) is to list QL skills or topics. As noted in the "Case for Quantitative Literacy" in Mathematics and Democracy, "A list of skills is ... comforting ... because skills are more immediately recognizable as something taught and learned in school" (Steen 2001, p. 15). It provides another "dimension" (p. 16) to analyses of the meaning of QL. It "helps instructors plan curricula to cover important topics and helps examiners assess the desired balance of knowledge" (p. 16).

Two well-known and historically significant lists are reproduced in Appendix A for reference: the list of skills in Mathematics and Democracy (Steen, 2001) and the list of topics in an appendix of the Sons Report (Sons 1996). Although one is a list of skills, and the other is a list of topics, it is clear that they both are getting at the same thing: what mathematics do we want our students to be able to use and have facility with in order to interact effectively with their world? ${ }^{1}$ Of significance to this paper, both those lists were developed by teams of mathematicians.

The goal of this paper is to generate a list empirically from Spreadsheets Across the Curriculum (SSAC), a workshop-based NSF project (DUE 0442629) that aimed specifically to develop an educational resource to help teach QL (Vacher and Lardner 2010; Wetzel 2011). In essence, we asked the participants and resource team at the workshops to vote on what mathematical skills and concepts were most important to them in a course they teach. The vote was in a form of "voting with your feet." In other words, the participants and resource team made modules to cause students to use mathematics to solve a problem in context. What mathematical topics did those module-makers choose for their modules?

\section{Background}

SSAC modules are short PowerPoint presentations with embedded Excel spreadsheets that students develop to solve a problem in context. Briefly, they are elaborate word problems that aim to get students to use mathematics. The

\footnotetext{
${ }^{1}$ Skills, topics, concepts, issues, items-we used these more or less interchangeably through the project described here. Similarly we did not distinguish between mathematical skills for QL, quantitative skills, and QL skills, nor between QL, numeracy, and quantitative reasoning.
} 
modules were produced by the three annual one-week workshops (2005, 2006, 2007) and are housed in the General Collection ${ }^{2}$ of the SSAC Library ${ }^{3}$ of the SSAC Web site. ${ }^{4}$ The design, functionality, and style of the Web site are a consequence of SSAC's partnership in the Pedagogical Services project of the Science Education Resources Center (SERC) ${ }^{5}$ (NSF DUE 0532768).

The SSAC General Collection comprises 55 modules classified into 26 different Library of Congress categories (Vacher and Lardner 2010). There are 40 authors: $13 \frac{1}{2} 2$ from mathematics made 171/2 modules; 17 from natural science made 27 modules; and 91/2 from other fields made 101/2 modules. ${ }^{6}$ (Table 1 provides a further breakdown).

Table 1

Authors Across the Curriculum and the Number of Modules They Wrote

\begin{tabular}{lll}
\hline & Authors & Modules \\
\hline A. Mathematics & 12.5 & 16.5 \\
Mathematics & 1 & 1 \\
Quantitative Reasoning Center & 13.5 & 17.5 \\
Total Mathematics & & \\
B. Natural Science & & \\
Agriecology & 1 & 1 \\
Biology & 4 & 7 \\
Chemistry & 4 & 6 \\
Environmental Science & 2 & 2 \\
Geology & 5 & 10 \\
Marine Science & 1 & 1 \\
Science & 17 & 27 \\
Total Natural Scies & & \\
C. Other & & \\
Business, including accounting & 2 & 3 \\
Communications/ESL & 1 & 1 \\
Computer literacy & 1 & 1 \\
Economics & 1 & 1 \\
English* & 0.5 & 0.5 \\
ESL & 1 & 1 \\
Human Services & 1 & 1 \\
Nursing & 1 & 1 \\
Sociology & 1 & 1 \\
Total Other & 9.5 & 10.5 \\
\hline
\end{tabular}

The purpose of the SSAC project, and hence of the modules, was to use context to develop facility with elementary mathematics (i.e., QL). To emphasize

\footnotetext{
2 http://serc.carleton.edu/sp/ssac_home/general/index.html

3 http://serc.carleton.edu/sp/ssac_home/design.html

4 http://serc.carleton.edu/sp/ssac_home/index.html

5 http://serc.carleton.edu/sp/service/index.html

6 The half authors and half modules result from a single module co-authored by Bridget Gold (math) and Rebecca Foster (Writing Center), "Is it an easy read: Calculating the readability of a text.".
} 
that purpose, we asked the authors to list the mathematics skills practiced in their modules in a prominent position on the title slide of the PowerPoint (Fig. 1a) under a heading such as Quantitative Concepts and Skills. This was in keeping with the proof-of-concept project ${ }^{7}$ that preceded the SSAC project. For the second and third workshop, we asked participants to select one from their list and identify it as the Core Quantitative Concept or Skill, and list the others as Supporting Quantitative Concepts and Skills (Fig 1b). This was part of an effort to focus attention on the need to align assessment questions, which participants were asked to develop for their modules, with the main learning goal of the module, which was supposed to be the core quantitative concept or skill.
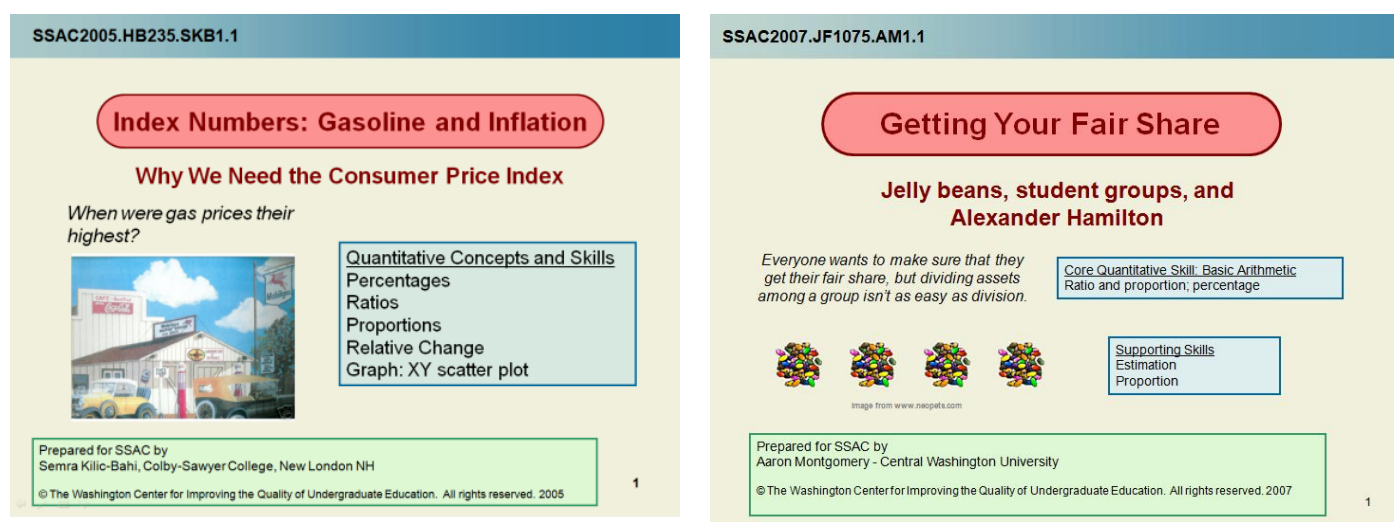

Figure 1. Title pages of a module created at the 2005 workshop (A) and a module created at the 2007 workshop (B).

Identifying the quantitative concepts and skills on the title slide dovetailed with a feature of the Web sites of SERC's Pedagogical Services portal. Each of those Web sites centers on a pedagogy; in the case of SSAC, the pedagogy is teaching with Spreadsheets Across the Curriculum. ${ }^{8}$ The Pedagogical Services Web sites include a set of examples, typically resources illustrating the pedagogy, and an overlying browse page from which users can find and select examples to download. In the case of SSAC, the examples are the modules (organized now into three collections, one of which is the General Collection), and its browse page $^{9}$ (Fig. 2) includes a search box labeled Quantitative Concepts. There are two other search boxes: one for Subject, and the other for Excel Skills. These search boxes allow the user to "narrow the view"-clicking on a term in the search box prompts the browse page to list the modules that are tagged with that term. We began developing the three vocabularies with the second workshop, a month after

\footnotetext{
${ }^{7}$ http://www.evergreen.edu/washcenter/modules/start.htm Modules for Geological Mathematical Problem Solving (NSF DUE 0126500)

${ }^{8}$ http://serc.carleton.edu/sp/ssac/index.html

${ }^{9}$ http://serc.carleton.edu/sp/ssac_home/general/examples.html
} 
SSAC became a partner in SERC's Pedagogical Services project. The Quantitative Concepts vocabulary was by far the greatest challenge of the three.

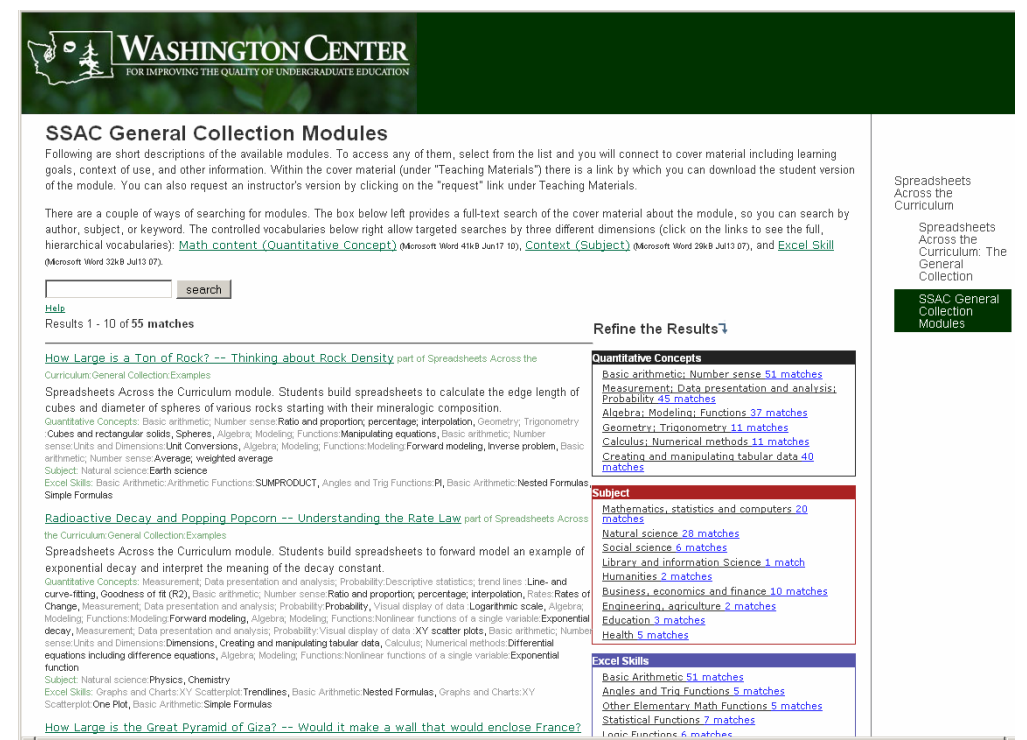

Figure 2. Screen shot of the start of the browse page listing the modules in the General Collection. The black-, red-, and blue-topped boxes are the search boxes for Quantitative Concepts, Subject, and Excel Skills, respectively.

\section{SSAC's Quantitative Concepts Search Vocabulary}

Although the vast majority of the time at the workshops was devoted to making the modules, we had daily, short, plenary sessions to discuss and brainstorm about issues of common concern. For the 2006 and 2007 workshops, one of these was "the vocabulary project," by which we meant developing a list of quantitative skills and concepts to use to tag the modules. The rules for the search vocabulary were established from the experience of SERC with their other Web sites. The main rule was that the list, although it could be a hierarchical classification, could not have more than about eight choices at any particular level so that users would not be overwhelmed. Also, the subdivisions need not be exhaustive of the higherlevel term or mutually exclusive of others at the same level. Third, the same term could appear in more than one branch, although in practice we did not use this liberating notion.

For the 2006 workshop, the discussion focused on the desirability to coordinate the quantitative skills and concepts identified on the title slide with the search vocabulary to tag the modules and differences between a list for mathematics topics vs. a list one for mathematics skills and concepts for QL. For 
the 2007 workshop, one of us (HLV) developed a classification scheme from the concepts and skills that had been listed on the 2005 and 2006 modules along with some terms that he believed could be useful for new modules that might be developed at the workshop. The classification consisted of five major headings (first-order tags):

1. Basic arithmetic and number sense (including seven second-order tags);

2. Measurement, data presentation and analysis, and probability (including seven second-order tags, three of which were subdivided into 4-5 third-order tags);

3. Algebra, modeling, and function (including six second-order tags and 15 third-order tags);

4. Geometry and trigonometry (including seven second-order tags);

5. Calculus and numerical methods (including five second-order tags).

Participants at the 2007 workshop were asked to use that vocabulary to identify the quantitative concepts and skills on their title pages. Although the participants tried to comply with the request, many found that they needed more labels. They ended up adding a major heading (Creating and manipulating tabular data) and 12 second- and third-order tags distributed through the taxonomy.

The result of this "grass-roots" effort to develop a list of mathematical skills and concepts to label and search the modules is shown in Table 2. We have no doubt that had there been additional workshops producing more modules, that there would have been additional refinements, including additional terms. The rest of this paper concerns counts of the modules that used the terms in Table 2.

\section{Data and Observations}

After the 2007 workshop and well into 2009, authors and the USF editing team finalized the modules. In 2010, the USF editing team finalized the General Collection pages including retagging all the modules with the vocabulary of Table 2. A tabulated summary of the modules and their tags is included here as a Supplemental File, "Catalog data for the SSAC General Collection." The rows identify the 55 individual modules and are grouped by Library of Congress category. The columns are: (1) the module's code number (see Vacher and Lardner 2010), (2) a screen shot of the title page (which links to the online module), (3) title (4) author, (5) quantitative skills and concepts listed on the title page, with the core one underlined, and (6) the terms of Table 2 used to tag the modules. Columns 5 and 6 are the raw data for the counts presented in the rest of this paper. 
Table 2

SSAC Search Vocabulary for Quantitative Skills

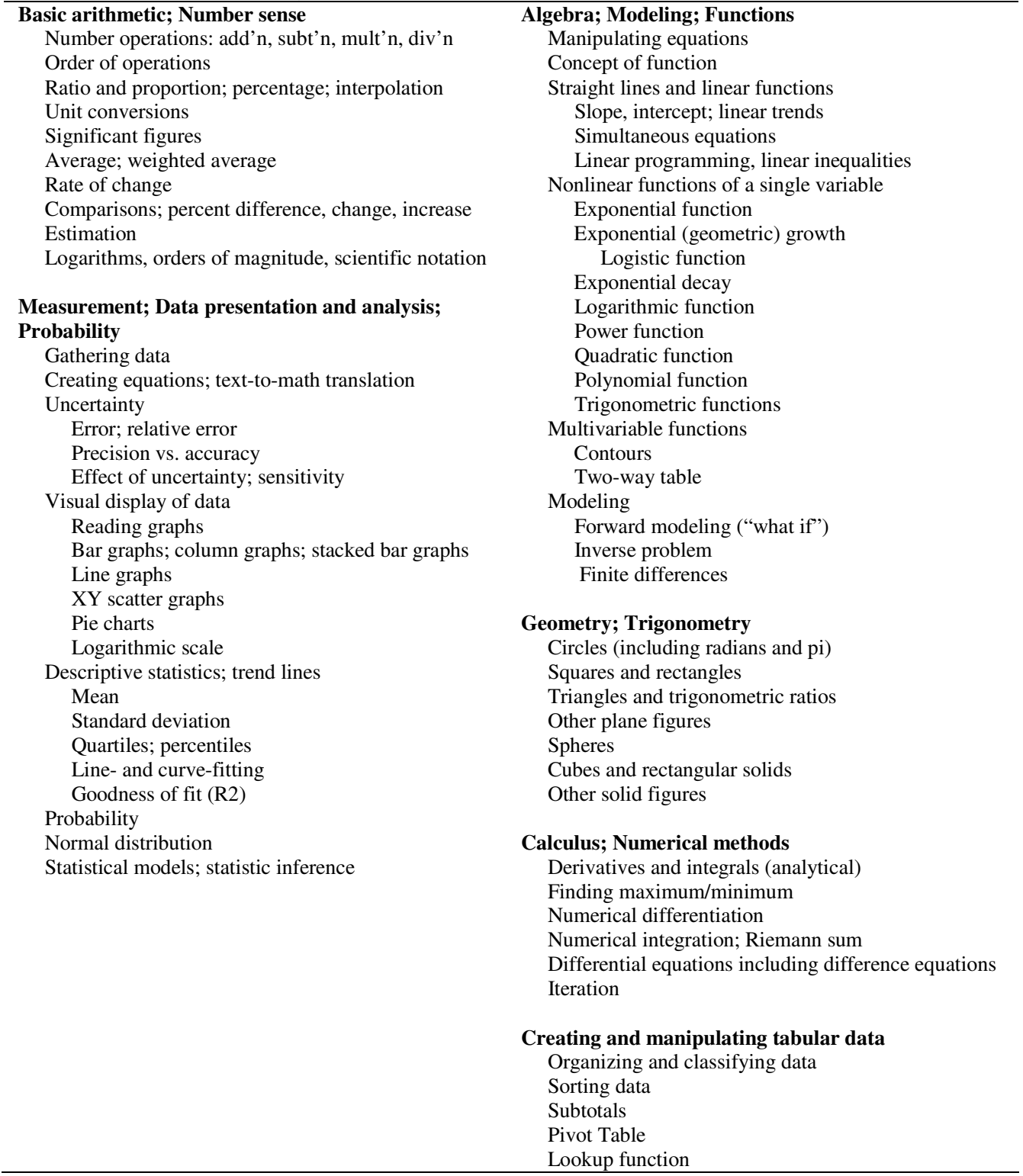

\section{Core Concepts}

Table 3 inventories the core quantitative concepts and skills identified by the authors on the cover pages of their modules. There are 27 different items for the 55 modules. Easily the most popular topic was ratio and proportion, which was selected and identified as the core concept for nine $(16 \%)$ of the modules. That 
one together with the next five (forward modeling, weighted average, estimation, rate of change, and unit conversion, all of with three or more "votes") were selected and identified on a total of $28(51 \%)$ of the modules. Seventeen of the 27 concepts and skills that were named got a single vote.

\section{Table 3}

\section{Inventory of Core Quantitative Concepts and Skills}

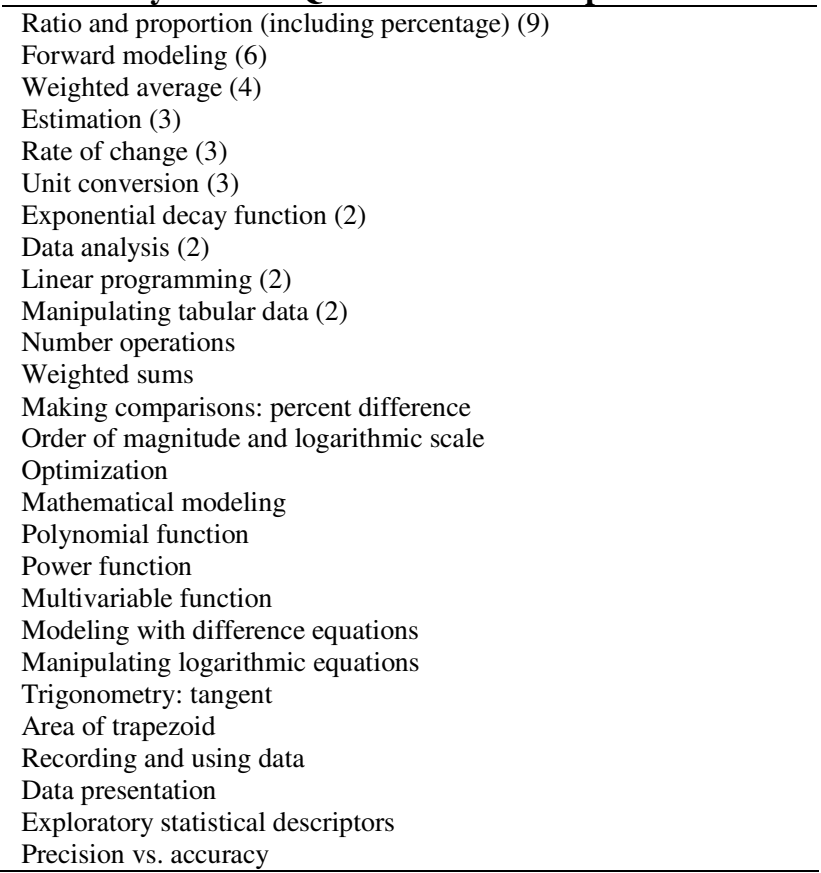

Comparison of the rather scatter shot list generated from the module cover pages (Table 3) with the classification developed for tagging the modules (Table 2) illustrates the desirability of developing a controlled vocabulary for a project such as SSAC. Even so, Table 3 clearly argues that ratio and proportion, modeling, weighted average, estimation, rates of change, and unit conversions belong on a list of mathematical concepts and skills for QL.

\section{From the Tags}

Appendix B tabulates the number of modules that are tagged with the various search vocabulary terms of Table 2 . Eight of the higher-order terms were used on $14(25 \%)$ or more of the 55 modules. These eight most popular topics are listed in Table 4. Ratio and proportion is again the clear winner, being used as a tag on $33(60 \%)$ of the modules. 


\section{Table 4}

QL Topics Most Frequently Used as Tags

Ratio and proportion; percentage; interpolation (33)

XY scatter graphs (26)

Rates (25)

Forward modeling (25)

Manipulating equations (19)

Unit conversions (18)

Creating equations; text-to-math translation (14)

Logarithms, orders of magnitude, scientific notation (14)

Appendix $\mathrm{B}$ also breaks down the data according to the discipline of the authors, using the three main classes of Table $1^{10}$ (Math, Natural Science, and Other). Table 5 lists the tags for each group that were used by about $30 \%$ or more of the modules written by each group of authors. "Ratio and proportion" is number 1 or 2 on each list, and "Rates" are on each list. Visual display of data is high on each list too, but for the Math and Natural Science groups, the choice is "XY scatter plots" and for Other, it is "Bar graphs." "Forward modeling" is also a favorite of both the Math and Natural Science groups. Aside from these commonalities, the combined lists also include "Estimation" and "Exponential growth" selected by the Math group; "Manipulating equations," "Unit conversions," "Logarithms; orders of magnitude; scientific notation," and "Line and curve-fitting" selected by the Natural Science group; and "Percent difference" selected by the Other group.

Table 5

Tag Counts by Discipline of Authors

\begin{tabular}{lll}
\hline Math (17 modules) & Natural Science (27 modules) & Other (11 modules) \\
\hline Ratio and proportion (11) & XY scatter plots (16) & Ratio and proportion (7) \\
Forward modeling (11) & Ratio and proportion (15) & Bar graphs (5) \\
Rates (8) & Manipulating equations (14) & Rates (4) \\
XY scatter (8) & Forward modeling (13) & Percent difference (3) \\
Estimation (5) & Rates (13) & \\
Exponential growth (5) & Unit conversions (13) & \\
& Logarithms; orders of magnitude (12) & \\
& Line and curve-fitting (9) & \\
\hline
\end{tabular}

\section{A Composite List of Topics}

Combining the authors' top six preferences for the core concepts and skills (Table 3 ) and the terms most frequently used to tag the modules (Tables 4 and 5) produces a composite list of 15 topics identified in the SSAC vocabulary project. The list is shown in Table 6, grouped and ordered as they might be in a course.

\footnotetext{
${ }^{10}$ For this exercise, we count the module by Rebecca Foster and Bridget Gold as an "other," consistent with the subject (see footnote 6)
} 
The first group of six is basic topics (40\% of the total) involving elementary arithmetic calculations, mostly using ratios in a variety of ways. The second group develops skills related to the sizes of quantities. The third represents visual presentation of data. The fourth works with equations and functions.

Table 6

Compiled List

1

Ratio and proportion; percentage

Percent difference

Rates

Rates of change

Unit conversions

Averages; weighted average

2

Orders of magnitude; logarithms

Estimation

3

Bar graphs

$\mathrm{XY}$ scatter plots

4

Creating equations; text-to-math translation

Manipulating equations

Forward modeling

Exponential growth

Line and curve-fitting

\section{Discussion}

Comparing Table 6 with the lists from Mathematics and Democracy and the Sons Report (Appendix A) shows considerable overlap, of course. Ratio and proportion; percent difference (or change); rates, and rates of change; averages; estimation; graphs; modeling; exponential growth (or change); linear fits-these are all widely recognized in the mathematics for QL. It would have been surprising if those did not bubble up in this exercise.

The comparison, however, reveals a few that are not commonly mentioned in connection with QL: unit conversions; logarithms (viz. orders of magnitude, scientific notation); and manipulating equations. Looking back at Table 5 shows that these are choices from the natural science authors, and the choices were in numbers rivaling those of ratio and proportion. This is not surprising. It is difficult_-some would say impossible — to teach science for meaning even at the introductory level if students cannot rearrange simple equations, convert units, or think in terms of the very large and very small.

Curiously, descriptive statistics and probability are underrepresented relative to their popularity on the lists of Appendix A. We doubt that SSAC authors 
believe that descriptive statistics and probability are not important either for QL or their courses; yet, they did not make many modules to help their students learn that material. This is a puzzle to us. It may reflect the nature of the experiment, namely the project's emphasis on spreadsheets and, in our workshops, the characterization of SSAC modules as elaborate word problems for mathematics in context. Likely had we worked the word "research" into the conversations, or had examples of modules using larger-than-screen-size data sets, or examples of modules that could be coupled to a lab or field component, or been more successful in attracting participants from the social sciences and economics, then, yes, there may well have been more modules developed to support exploratory data analysis beyond simply line-fitting. The emphasis on SSAC modules as word problems may also have contributed to the large number of modules for forward modeling, possibly at the expense of statistics. Regardless of the reason for the small number of modules for descriptive statistics and probability in the General Collection, the result gives direction for modules in future SSAC collections.

\section{Conclusions}

In order to know what to include in QL programs, one needs to know what topics instructors with different backgrounds think are important in their courses. The SSAC modules provide a poll of sorts - 55 ballots (modules) from 40 authors, with multiple mathematical skills and concepts selected on each ballot. About half of the ballots are from natural science disciplines.

Overall there was broad agreement between the SSAC votes and classic published QL lists about the importance of such topics as ratio and proportion; rates and rates of change; graphs (bar graphs and XY-scatter plots); and modeling. The ballots from natural science suggest three more of first-order importance: unit conversions (easily added to ratios and proportion); logarithms (for orders of magnitude and scientific notation); and manipulating equations (more precisely, rearranging simple equations, even ones dealing with proportions).

\section{Acknowledgments}

We thank the four reviewers for their so-called minor revisions, which led to substantial changes and more interesting findings; Denise Davis who did the retagging and counting and created the "card catalog" in the supplemental file; and all 40 authors for their modules and interest in our vocabulary project. 


\section{References}

Cohen, Patricia Cline. 2001. The emergence of numeracy. In Mathematics and democracy, ed. L. A. Steen, 23-29. Princeton, NJ: National Council on Education and the Disciplines.

Cohen, Patricia Cline. 1999. A calculating people: The spread of numeracy in early America. New York: Routledge.

MacNeal, Edward. 1994. Mathsemantics: Making numbers talk sense. New York: Viking Penguin.

Sons, Linda 1996. Quantitative Reasoning for College Graduates: A Supplement to the Standards. Washington D.C.: Mathematical Association of America.

Steen, Lynn Arthur, ed. 2001. Mathematics and Democracy: The case for Quantitative Literacy. Princeton, NJ: National Councilon Education and the Disciplines. http://www.maa.org/q1/mathanddemocracy.html (accessed December 28, 2010).

Vacher, H.L., and E. Lardner. 2010. Spreadsheets across the curriculum, 1: The idea and the resource. Numeracy 3(2): Article 6. http://dx.doi.org/10.5038/1936-4660.3.2.6. (accessed December 28, 2010).

Wetzel, L. R. 2011. Spreadsheets across the curriculum, 2: Assessing our success with students at Eckerd College. Numeracy 4(1): Article 4. http://dx.doi.org/10.5038/1936-4660.4.1.4.

\section{Appendix A. Selected Lists of QL Skills and Topics}

Table A1. Skills Included in QL (Steen 2001, p. 16-17)

\begin{tabular}{ll}
\hline Arithmetic & $\begin{array}{l}\text { Having facility with simple mental arithmetic; estimating arithmetic calculations; reasoning with } \\
\text { proportions; counting by indirection (combinatorics). }\end{array}$ \\
\hline Data & $\begin{array}{l}\text { Using information conveyed as data, graphs and charts; drawing inferences from data; recognizing } \\
\text { disaggregation as a factor in interpreting data. }\end{array}$ \\
\hline Computers & $\begin{array}{l}\text { Using spreadsheets; recording data, performing calculations, creating graphic displays, extrapolating, } \\
\text { fitting lines or curves to data. }\end{array}$ \\
\hline Modeling & $\begin{array}{l}\text { Formulating problems, seeking patterns, and drawing conclusions; recognizing interactions in } \\
\text { complex systems; understanding linear, exponential, multivariate, and simulation models; } \\
\text { understanding the impact of different rates of growth. }\end{array}$ \\
\hline Statistics & $\begin{array}{l}\text { Understanding the importance of variability; recognizing the differences between correlation and } \\
\text { causation, between randomized experiments and observational studies; between finding no effect and } \\
\text { finding no statistical effect (especially with small samples), and between statistical significance and } \\
\text { practical importance (especially with large samples). }\end{array}$ \\
\hline Chance & $\begin{array}{l}\text { Recognizing that seemingly improbable coincidences are not uncommon; evaluating risks from } \\
\text { available evidence; understanding the value of random samples. }\end{array}$ \\
\hline Reasoning & $\begin{array}{l}\text { Using logical thinking; recognizing levels of rigor in methods of inference; checking hypotheses; } \\
\text { exercising caution in making generalizations. }\end{array}$ \\
\hline
\end{tabular}

Table A2. Mathematical Topics for QL from the Sons Report 


\section{(adapted from Sons 1996, Appendix B)}

\begin{tabular}{|c|c|}
\hline Arithmetic & $\begin{array}{l}\text { Estimation } \\
\text { Percentage change } \\
\text { Use of calculator: rounding and truncation errors; order of operations. }\end{array}$ \\
\hline Geometry & $\begin{array}{l}\text { Measurement: units and conversion of systems; length; area; volume. } \\
\text { "Familiar" shapes: rectangles, triangles, circles, cubes, cones, cylinders, spheres, the Pythagorean } \\
\text { relationship. } \\
\text { Angles: slopes of lines; parallel and perpendicular lines; right angles; similarity. } \\
\text { Complex shapes: approximation by "familiar" shapes; solution region for a system of linear } \\
\text { inequalities in a plane. }\end{array}$ \\
\hline Algebra & $\begin{array}{l}\text { Linear equations: equations in one unknown; systems of two unknowns; methods of solution. } \\
\text { Proportionality } \\
\text { Graphs and tables: constructing; reading, interpreting; extrapolating from; the notions of direct and } \\
\text { indirect variation. } \\
\text { Simple exponents: roots and powers; products and quotients with common base. } \\
\text { Concept of function: constructing discrete and continuous functions; graphical representation of } \\
\text { functions; zeroes of functions. }\end{array}$ \\
\hline Statistics & $\begin{array}{l}\text { Experimental probability: counting; mutually exclusive and independent variables. } \\
\text { Graphical displays of data: pie and bar charts; frequency polygons; visual impact of scale changes. } \\
\text { Central tendency and spread: comparison of data sets using mean, median, mode and standard } \\
\text { deviation; quartile deviation, range; percentile rank. } \\
\text { Correlation: measuring and evaluating the relationship between two variables. } \\
\text { Common sources of error: sampling error; misinterpreting averages or probabilities; invalid } \\
\text { comparison distributions; statistical significance; statistical "proof". } \\
\text { Random sampling: count-recount technique; polls; lotteries; fair representation. } \\
\text { Linear fit: Comparison of fit of two lines to a data set. } \\
\text { Quality control: the binomial distribution } \\
\text { Simulation } \\
\text { Confidence intervals*: interval estimates; the standard error of the mean. }\end{array}$ \\
\hline Other & $\begin{array}{l}\text { Exponential change } \\
\text { Rates: comparison of average rate of change } \\
\text { Models } \\
\text { Algorithms: sequential thinking; construction; relationship to formulas } \\
\text { Optimization: the notions of maxima and minima of functions with our without constraints; graphical } \\
\text { and computational methosds for finding them; simple analuytic methods, such as completing the } \\
\text { square for quadratic polynomials. } \\
\text { Linear programming*: systems of equations in two variables with linear objective function } \\
\text { Scheduling* } \\
\text { Networks* }\end{array}$ \\
\hline
\end{tabular}




\section{Appendix B. Counts of Tags}

Modules are broken down by discipline of the authors. For example, 16 of the 17 modules authored by mathematicians are tagged with "Basic arithmetic; Number sense." Also, 11 of the 33 modules in the General Collection that were tagged with "Ratio and proportion; percentage; interpolation" were authored by mathematicians.

\begin{tabular}{|c|c|c|c|c|}
\hline & $\begin{array}{c}\text { Total } \\
(55)\end{array}$ & $\begin{array}{c}\text { Math } \\
(17)\end{array}$ & $\begin{array}{c}\text { Nat Sci } \\
(27)\end{array}$ & $\begin{array}{c}\text { Other } \\
(11)\end{array}$ \\
\hline Basic arithmetic; Number sense & 51 & 16 & 27 & 8 \\
\hline Number operations: add'n, subt'n, mult'n, div'n & 12 & 4 & 6 & 2 \\
\hline Order of operations & 1 & 0 & 0 & 1 \\
\hline Ratio and proportion; percentage; interpolation & 33 & 11 & 15 & 7 \\
\hline Units and dimensions & 23 & 5 & 16 & 2 \\
\hline Unit conversions & 18 & 3 & 13 & 2 \\
\hline Dimensions & 3 & 1 & 2 & 0 \\
\hline Significant figures & 6 & 1 & 5 & 0 \\
\hline Average; weighted average & 9 & 3 & 4 & 2 \\
\hline Rates & 25 & 8 & 13 & 4 \\
\hline Rate of change & 11 & 3 & 8 & 0 \\
\hline Comparisons; percent difference, change, increase & 9 & 3 & 3 & 3 \\
\hline Estimation & 11 & 5 & 4 & 2 \\
\hline Logarithms, orders of magnitude, scientific notation & 14 & 2 & 12 & 0 \\
\hline Measurement; Data presentation and analysis; Probability & 45 & 12 & 24 & 9 \\
\hline Gathering data & 4 & 1 & 1 & 2 \\
\hline Creating equations; text-to-math translation & 14 & 4 & 7 & 3 \\
\hline Uncertainty & 2 & 0 & 2 & 0 \\
\hline Error; relative error & 1 & 0 & 1 & 0 \\
\hline Precision vs. accuracy & 1 & 0 & 1 & 0 \\
\hline Effect of uncertainty; sensitivity & 2 & 0 & 2 & 0 \\
\hline Visual display of data & 37 & 9 & 20 & 8 \\
\hline Reading graphs & 8 & 1 & 5 & 2 \\
\hline Bar graphs; column graphs; stacked bar graphs & 8 & 0 & 3 & 5 \\
\hline Line graphs & 2 & 0 & 1 & 1 \\
\hline $\mathrm{XY}$ scatter graphs & 26 & 8 & 16 & 2 \\
\hline Pie charts & 3 & 0 & 2 & 1 \\
\hline Logarithmic scale & 5 & 0 & 5 & 0 \\
\hline Descriptive statistics; trend lines & 15 & 4 & 11 & 0 \\
\hline Mean & 2 & 0 & 2 & 0 \\
\hline Median; mode & 1 & 0 & 1 & 0 \\
\hline Standard deviation; variance; range & 3 & 0 & 3 & 0 \\
\hline Quartiles; percentiles & 1 & 0 & 1 & 0 \\
\hline Line- and curve-fitting & 13 & 4 & 9 & 0 \\
\hline Goodness of fit (R2) & 5 & 2 & 3 & 0 \\
\hline Probability & 2 & 0 & 2 & 0 \\
\hline Normal distribution & 1 & 0 & 1 & 0 \\
\hline Statistical models; statistic inference; sampling & 4 & 0 & 4 & 0 \\
\hline
\end{tabular}




\begin{tabular}{|c|c|c|c|c|}
\hline Algebra; Modeling; Functions & 37 & 12 & 22 & 3 \\
\hline Manipulating equations & 19 & 3 & 14 & 2 \\
\hline Functions: general & 2 & 2 & 0 & 0 \\
\hline Concept of function & 1 & 1 & 0 & 0 \\
\hline Zeroes of function & 1 & 1 & 0 & 0 \\
\hline Straight lines and linear functions & 10 & 3 & 6 & 1 \\
\hline Slope, intercept; linear trends & 8 & 1 & 6 & 1 \\
\hline Simultaneous equations & 2 & 1 & 1 & 0 \\
\hline Linear programming, linear inequalities & 2 & 1 & 0 & 1 \\
\hline Nonlinear functions of a single variable & 17 & 7 & 10 & 0 \\
\hline Exponential function & 9 & 3 & 6 & 0 \\
\hline Exponential (geometric) growth & 7 & 5 & 2 & 0 \\
\hline Logistic function & 2 & 1 & 1 & 0 \\
\hline Exponential decay & 3 & 0 & 3 & 0 \\
\hline Logarithmic function & 3 & 1 & 2 & 0 \\
\hline Power function & 5 & 2 & 3 & 0 \\
\hline Quadratic function & 2 & 2 & 0 & 0 \\
\hline Polynomial function & 1 & 1 & 0 & 0 \\
\hline Trigonometric functions & 0 & 0 & 0 & 0 \\
\hline Multivariable functions & 7 & 2 & 3 & 2 \\
\hline Contours & 1 & 1 & 0 & 0 \\
\hline Two-way table & 1 & 0 & 1 & 0 \\
\hline Modeling & 28 & 11 & 16 & 1 \\
\hline Forward modeling ("what if") & 25 & 11 & 13 & 1 \\
\hline Inverse problem & 7 & 1 & 6 & 0 \\
\hline Finite differences & 1 & 0 & 1 & 0 \\
\hline Geometry; Trigonometry & 11 & 3 & 8 & 0 \\
\hline Circles (including radians and pi) & 5 & 1 & 4 & 0 \\
\hline Squares and rectangles & 2 & 1 & 1 & 0 \\
\hline Triangles and trigonometric ratios & 2 & 1 & 1 & 0 \\
\hline Other plane figures & 2 & 1 & 1 & 0 \\
\hline Spheres & 3 & 0 & 3 & 0 \\
\hline Cubes and rectangular solids & 4 & 2 & 2 & 0 \\
\hline Other solid figures & 1 & 0 & 1 & 0 \\
\hline Calculus; Numerical methods & 11 & 5 & 5 & 1 \\
\hline Derivatives and integrals (analytical) & 2 & 1 & 1 & 0 \\
\hline Finding maximum/minimum & 5 & 3 & 1 & 1 \\
\hline Numerical differentiation & 0 & 0 & 0 & 0 \\
\hline Numerical integration; Riemann sum & 1 & 0 & 1 & 0 \\
\hline Differential equations including difference equations & 4 & 1 & 3 & 0 \\
\hline Iteration & 3 & 2 & 1 & 0 \\
\hline Creating and manipulating tabular data & 40 & 14 & 18 & 8 \\
\hline Organizing and classifying data & 3 & 0 & 1 & 2 \\
\hline Sorting data & 4 & 2 & 1 & 1 \\
\hline Subtotals & 1 & 1 & 0 & 0 \\
\hline Pivot Table & 2 & 0 & 0 & 2 \\
\hline Lookup function & 3 & 2 & 0 & 1 \\
\hline
\end{tabular}

